\title{
STUDY ON SHEAR STRENGTH CHARACTERISTICS OF COIR MAT REINFORCED SAND
}

\author{
Sridhar $\mathbf{R}^{1}$, M.T.Prathapkumar ${ }^{2}$ \\ ${ }^{1}$ Research Scholar, Ghousia college of Engg \& Assoc. Professor, Department of Civil Engg, Alva's Institute of Engg \& \\ Technology, Moodbidri, Karnataka, India \\ ${ }^{2}$ Professor, Department of Civil Engg, Reva Institute of Technology \& Management, Karnataka, India
}

\begin{abstract}
Soil reinforcement technique is one of the most popular techniques used for improvement of poor soils. Metal strips, synthetic geotextiles, geogrid sheets, natural geotextiles, randomly distributed, synthetic and natural fibers are being used as reinforcing materials to soil. Further, the soil reinforcement causes significant improvement in tensile strength, shear strength, other properties, bearing capacity as well as economy. This is a relatively simple technique for ground improvement and has tremendous potential as accost effective solution to many geotechnical problems. The objective of the present investigation is to determine the effect of introducing coir mat reinforced soil layer over soil stratum and effect of size of the opening of coir mat on shear strength characteristics of sand will be analysed.
\end{abstract}

Key Words: Soil reinforcement, Shear strength, Coir mat.

\section{INTRODUCTION}

Soil reinforcement technique is one of the most popular techniques used for improvement of poor soils. Metal strips, synthetic geotextiles, geogrid sheets, natural geotextiles, randomly distributed, synthetic and natural fibres are being used as reinforcing materials to soil. Further, the soil reinforcement causes significant improvement in tensile strength, shear strength, other properties, bearing capacity as well as economy. This is a relatively simple technique for ground improvement and has tremendous potential as accost effective solution to many geotechnical problems.

Coir is a $100 \%$ organic naturally occurring fiber, from a renewable source obtained from coconut [cocosnucifera] husk. Naturally resistant to rot, moulds and moisture, it is not treated with any chemicals during its spinning process for converting it into a yarn. Hard and strongest among all natural fibers, it can be spun and woven into different types of mattings and mats. Geotextiles made out of coir are ideally suited for low cost applications because coir is available in abundance.

\subsection{Interlocking Effect in Mat Reinforcement}

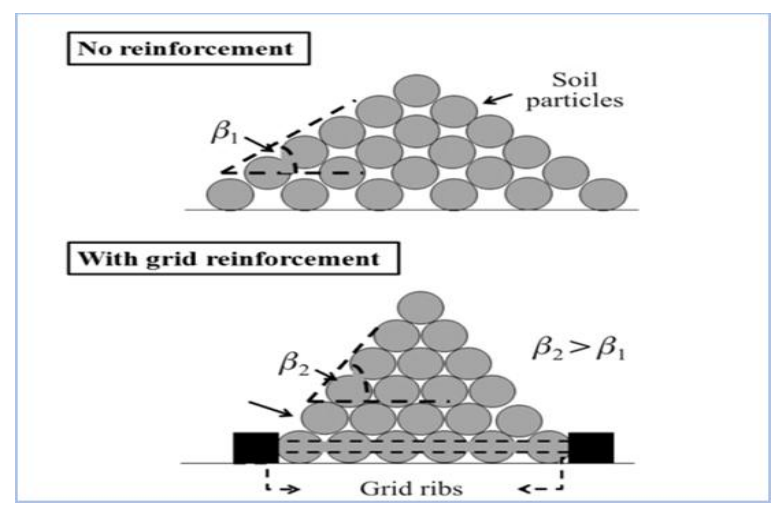

When grids/mats are used, aperture size of the grid, thickness and shape of rib cross section, extensibility of longitudinal ribs, flexibility and shear stiffness of transversal ribs, strength of knots matters Degree of interaction is influenced by interrelation of soil particles and structure of the grid: ratio between particle size and grid aperture size, ratio between particle size and diameter of transversal ribs of grid

\section{LITERATURE REVIEW}

Initial investigations were concerned with sub grades reinforced horizontally with several members of thin strips. [Binquet and Lee (1975), Sreekantaiah (1987, 1988), Mandal and Dixit (1986), Bergado, et.al (2001)]. Subsequently metal and coir rods [Milovic (1977, 1979), Zhenggui Wang \& Richwein (2002)], ropes and strips made of natural fibers 
[Akinmusuru \& Akinbolade (1981), Mandal \& Dixit (1986), Ramanatha Iyer (1988), Shankaraiah \& Narahari (1988)] Geosynthetics [Guido (1985, 1989), Singh \& Bindumadhava (1986), Saran (1985), Dembiki \& Jermolowicz (1988), Ramaswamy (1985), Hoe. I. Ling, et.al (2001)] were also used in investigations. In the above investigations optimization of the following variables have been tried and reported Praveenkumar Gupta, Swami saran and Ravikant Mittal $[2006]^{[2]}$ they conducted the series of direct shear test, they found out that the peak shear stress of Randomly distributed reinforced soil $\{$ RDFS $\}$ is more than that for the unreinforced sand. The effect of fiber content at low normal stress is more at relative density $50 \%$. As the fiber content increases the percentage increase in the peak shear stress increases up to $0.2 \% \mathrm{FC}$. Beyond $0.2 \% \mathrm{FC}$ rate of percentage increase in the peak shear stress starts decreasing. As the normal stress increases the increase in the peak shear stress of RDFS decreases. And for a given intensity, the settlement of unreinforced sand is more than that of the reinforced sand and the settlement reduces with the increase in fiber content. The bearing capacity of RDFS increases with increase in fiber content.

Wasti and Butun [1996]. A series of laboratory model tests on a strip footing supported by sand reinforced by randomly distributed Coir fiber and mesh elements was conducted in order to compare the results with those obtained from unreinforced sand and with each other. For conducting the model tests, uniforms and was compacted in the test box at its optimum moisture content and maximum dry density. Three types of reinforcement, two sizes of mesh elements having the same opening size and one size of fiber element cut from the meshes, were used in varying amounts in the tests.

Madhavi Latha and Vidya S. Murthy $[2006]^{[3]}$ conducted studies on the effects of reinforcement form on strength improvement of geosynthetic-reinforced sand through triaxial compression tests. Samples of sand reinforced with geosynthetics in three different forms, viz. horizontal layers, geocells, and randomly distributed discrete fibers are tested in triaxial compression, and results are analyzed to understand the strength improvement in sand due to reinforcement in different forms. Three types of geosynthetics-geotextile, geogrid, and polyester film are used for reinforcing sand in layer form. Two types of geosynthetics-geotextile and polyester film are used in tests on geocells. Polyester film is used in all the three forms of reinforcement viz. planar, cellular, and discrete fiber reinforcement.

\section{SCOPE OF PRESENT WORK}

The objective of the present investigation is to determine the effect of introducing coir mat reinforced soil layer over soil stratum. The results of the present experimental investigation will be analyses to determine the Effect of size of the opening of coir mat on shear strength characteristics of sand.

\section{MATERIALS}

\subsection{Sand}

Sand is a naturally occurring granular material composed of finely divided rock and mineral particles.

\subsection{Coir Mat}

Coir is a biodegradable organic fiber material which is rigid, strong, and tensile in nature. The rate of decomposition of coir is much less than any other natural fiber. Coir is a $100 \%$ organic fiber, from a renewable source coconut husk. Naturally resistant to rot, moulds and moisture, it needs no chemical treatment. Hard and strong, it can be spun and woven into matting. They also have the right strength and durability to protect the slopes from erosion, while allowing vegetation to flourish. They can dissipate the energy of flowing water and absorb the excess solar radiation. Coir is a one of the cheaply available organic material and for the present study coir mat was purchased from Karnataka coir board, Bangalore.

Coir mat with different opening size of $10 \mathrm{~mm}, 20 \mathrm{~mm}$ and $30 \mathrm{~mm}$ square size was procured from Karnataka coir industries Ltd, Bangalore.

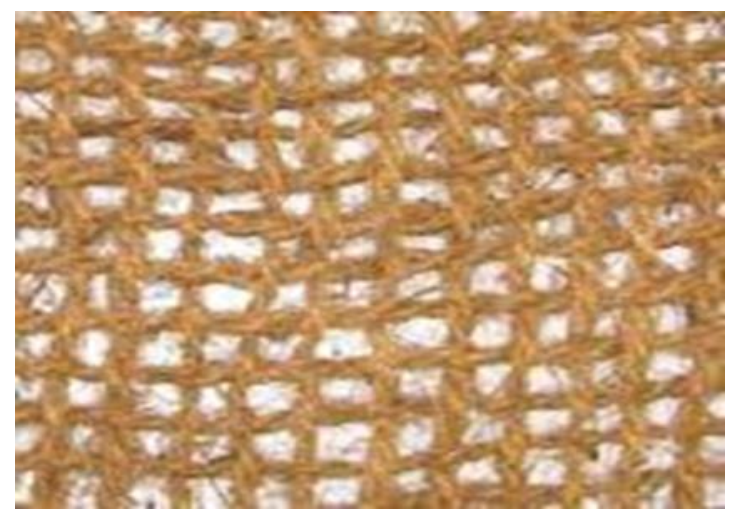

Fig 4.1 10mm opening size coir mat

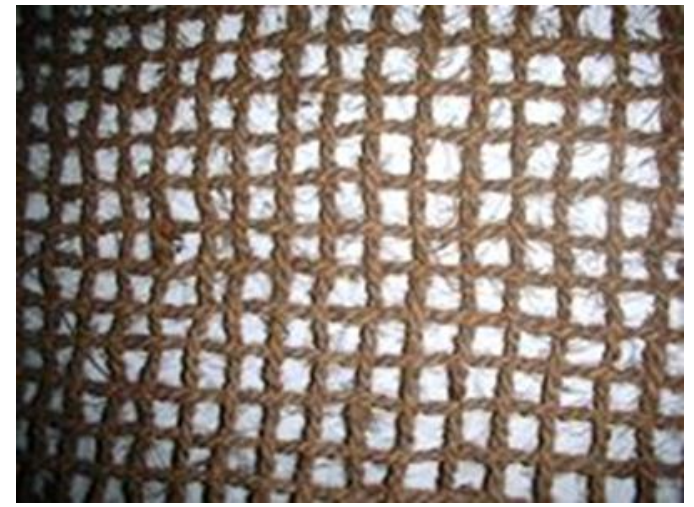

Fig 4.2 20mm opening size coir mat 


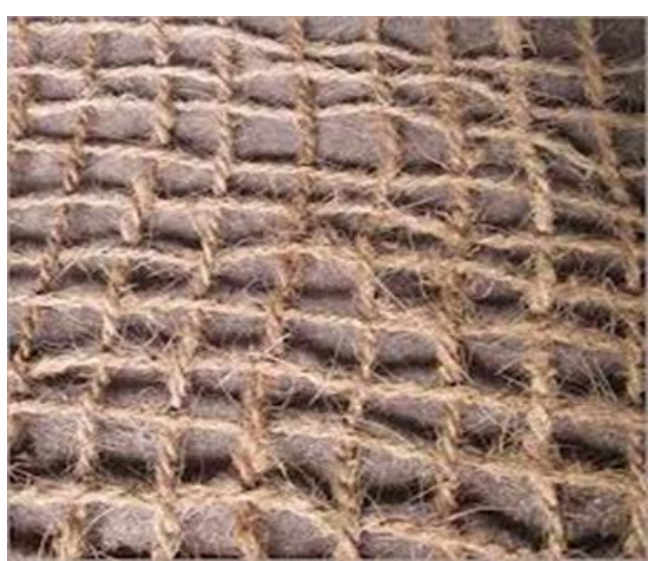

Fig 4.3 30mm opening size coir mat

\section{METHODOLOGY}

Direct Shear Test on Dry Sand with Randomly Distributed Coir Fibres of different Length and at Different Percentage.

Direct shear test were conducted on dry sand with Coir Mat Reinforcement at the interface of Failure Plane using specimen of size $60 \times 60 \times 25 \mathrm{~mm}$ depth in a direct shear box.

Fibre content was calculated on the basis of dry weight of sand, defined by, $\mathrm{Fc}=\mathrm{W}_{\mathrm{f}} / \mathrm{W}_{\mathrm{S}}$, Where $\mathrm{W}_{\mathrm{f}}$ is dry weight of fibres and $\mathrm{W}_{\mathrm{s}}$ is dry weight of sand. Initially unreinforced dry sand was compacted at $70 \%$ relative density and tested at three different normal stresses $50 \mathrm{KPa}, 100 \mathrm{KPa}$ and $150 \mathrm{KPa}$.

Similarly tests were conducted on randomly distributed coir reinforced sand of different lengths viz., $10 \mathrm{~mm}, 20 \mathrm{~mm}, 30 \mathrm{~mm}$ mixed and compacted to relative density of $70 \%$ and fibre content(FC) was varied from $0.05 \%, 0.1 \%, 0.2 \%$ and $0.3 \%$ each test was done at three different normal stresses 50KPa, $100 \mathrm{KPa}$ and $150 \mathrm{KPa}$.

The fibre added to sand was considered as a part of the solid fraction. The fibres were mixed by hand and transferred to the direct shear box.

Direct shear test were conducted on dry sand specimen of size $60 \times 60 \times 25 \mathrm{~mm}$. Coir mat was pasted on wooden plate of thickness $12.0 \mathrm{~mm}$ and was placed in the bottom half of the direct shear box, such that the coir mat was placed exactly in the plane of horizontal shear.

The sand in the upper half was compacted with dry sand at $70 \%$ relative density at three different normal stresses of $50 \mathrm{KPa}, 100 \mathrm{KPa}$ and $150 \mathrm{KPa}$.

A total of three direct shear tests were conducted to study the influence of coir mat with different size openings, viz $10 \mathrm{~mm}$, $20 \mathrm{~mm}$, and $30 \mathrm{~mm}$.
Desired compaction was achieved by light tamping, using circular iron rod

\section{RESULTS AND DISCUSSION}

\subsection{Effect of Size of Coir Mat Opening on Angle of Internal Friction (ø)}

The results of direct shear test conducted on unreinforced sand and reinforced sand with coir mat of 10,20 , and $30 \mathrm{~mm}$ size openings has been tabulated in Table 6.1. It is observed that increase in the size of the opening of the coir mat decreases the value of angle of internal friction.

The decrease in $\varnothing$ is significant when the size of the opening increases from $20 \mathrm{~mm}$ to $30 \mathrm{~mm}$

Table 6.1 Effect of Size of Coir Mat Opening on Angle of Internal Friction $(\varnothing)$

\begin{tabular}{|l|c|c|c|c|}
\hline \multirow{2}{*}{} & \multicolumn{4}{|c|}{ Coir mat opening in mm } \\
\cline { 2 - 5 } & unreinforced & $10 \times 10$ & $20 \times 20$ & $30 \times 30$ \\
\hline $\begin{array}{l}\varnothing \text { in } \\
\text { degrees }\end{array}$ & $33^{\circ}$ & $\mathbf{5 5}^{\circ}$ & $51^{\circ}$ & 48 \\
\hline
\end{tabular}

Results of the direct shear test on unreinforced sand has been ploted in terms of shear stress v/s normal stress in fig 6.1. sand reinforcement with different sized coir mat have been plotted in terms ofshear stress $\mathrm{v} / \mathrm{s}$ normal stress in Fig $6.2,6.3 \& 6.4$ shows the results of angle of internal friction $(\phi)$. Fig 6.5 shows comparetive values of angle of internal friction $(\phi)$.

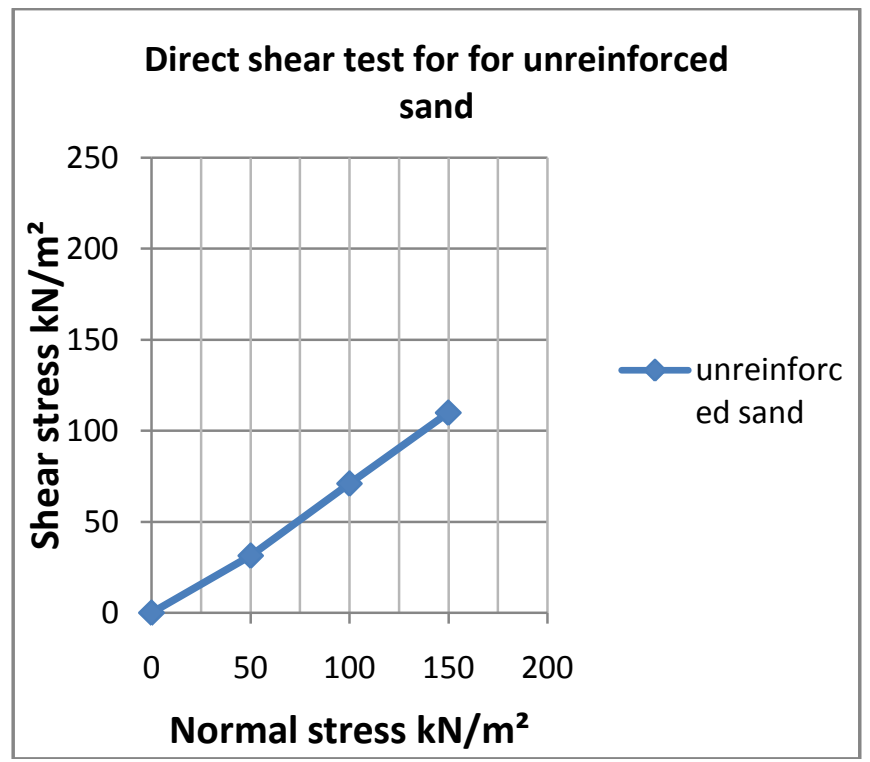

Fig 6.1 Direct Shea Test for Unreinforced Sand 


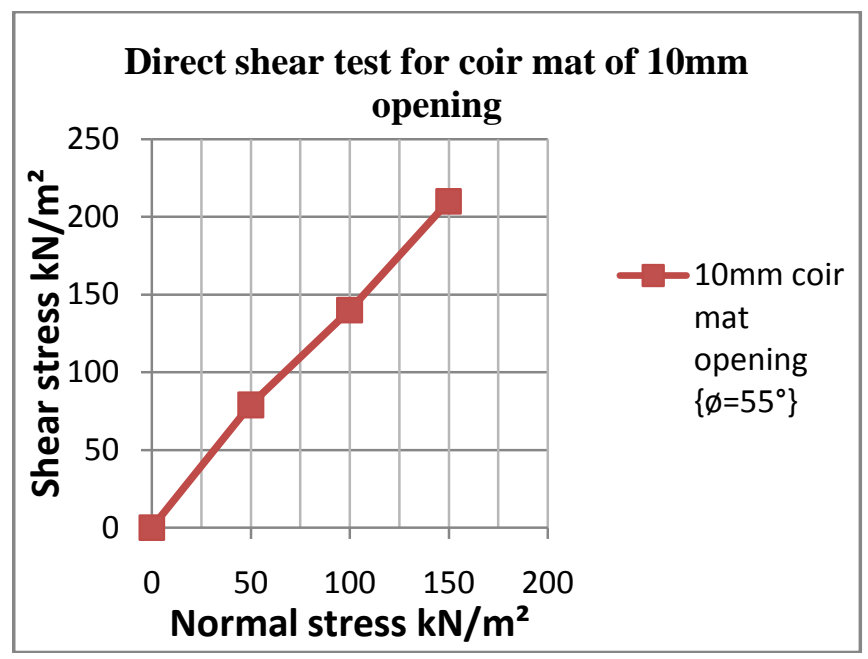

Fig 6.2 Direct Shea Test for Reinforced sand with Coir Mat of $10 \mathrm{~mm}$ opening

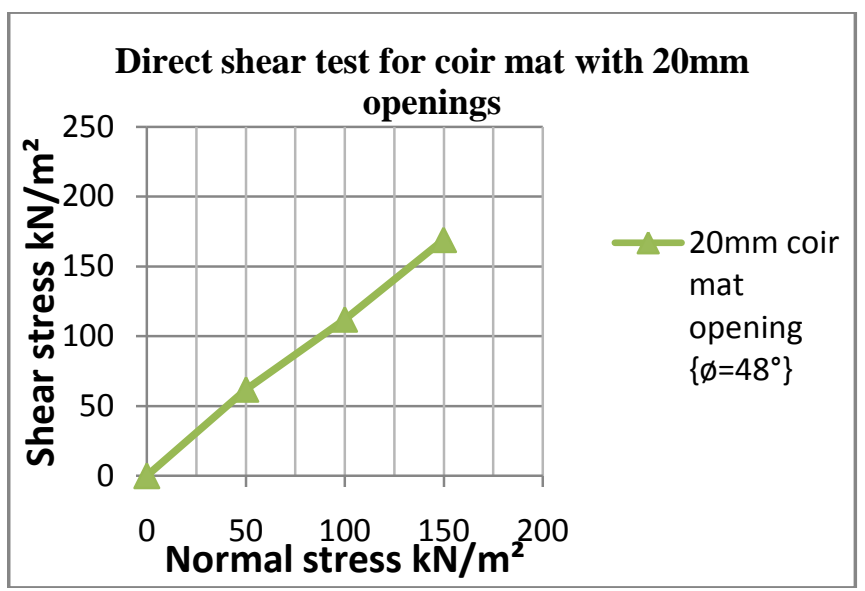

Fig 6.3 Direct Shea Test for Reinforced sand with Coir Mat of $20 \mathrm{~mm}$ opening

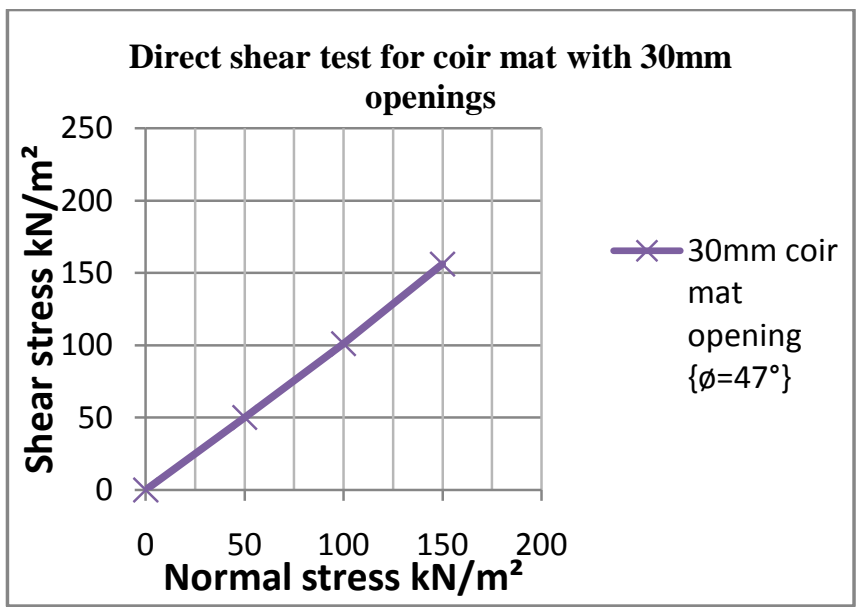

Fig 6.4 Direct Shea Test for Reinforced sand with Coir Mat of $30 \mathrm{~mm}$ opening



Fig 6.5 Direct Shear Test for Coir Mat with Different openings

\subsection{Effect of Coir Mat Opening on Peak Shear Stress}

Table 6.2 Effect of Coir Mat Opening on Peak Shear Stress

\begin{tabular}{|l|c|c|c|}
\hline $\begin{array}{l}\text { Coir mat } \\
\text { opening }\end{array}$ & \multicolumn{3}{|c|}{ Normal stress (kpa) } \\
\hline & $\mathbf{5 0}$ & $\mathbf{1 0 0}$ & $\mathbf{1 5 0}$ \\
\hline $10 \mathrm{~mm}$ & 184 & 107.30 & 151 \\
\hline $20 \mathrm{~mm}$ & 78 & 60.60 & 95.55 \\
\hline $30 \mathrm{~mm}$ & 68.90 & 54.74 & 87.35 \\
\hline
\end{tabular}

The following observations can be made the values of peak shear stress as for table 6.2

Maximum value of peak shear stress obtained corresponds to coir mat with $10 \mathrm{~mm}$ size opening.

The effect of increase in size of opening decreases the interlocking effect between sand particles and coir mat. Hence maximum $\emptyset$ value has been obtained corresponding to smaller size of the opening of coir mat.

Thus the size of the coir mat opening has significant influence on the shear strength characteristics of coir mat reinforced sand.

Smaller the size of opening, greater will be the strength mobilized.

\section{CONCLUSIONS}

The maximum value of $\varnothing$ has been obtained corresponding to smaller size of the square opening, i.e., at $10 \mathrm{~mm}$ coir mat opening. With increase in size of the opening, the value of $\varnothing$ decreases. This is because of possible reduction in interlocking 
effect between sand particles and coir mat due to increase in its size.

The value of $\varnothing$ obtained for coir mat reinforced sand is significantly larger than coir fibre reinforced. Hence, interlocking effect provided by the mat/grid type of reinforcement is better than the inclusion of fibres in sand. However, increase in size of the grid decreases the friction.

This result has significant implications in designing reinforced sand for many civil engineering applications.

\section{REFERENCES}

[1]. P. Vinod, Ajitha B. Bhaskar, S. Sreehari (2009), "Behavior of a square footing on loose sand reinforced with braided coir rope", Geotextiles and Geo-membranes, Vol. 27, 464-474.

[2]. Praveenkumar Gupta, Swami Saran and Ravikant Mittal (2006), "Behavior of Fibre reinforced sand in different test conditions", Indian Geotechnical Journal, Vol. 36, No. 3, 272282.

[3]. G. Madhavi Latha, Vidya S. Murthy (2007), "Effects of reinforcement form on the behavior of geosynthetic reinforced sand" Indian Institute of Science, Bangalore, India, Geotextiles and Geo-membranes, Volume 25, Issue 1, 23-32.

[4]. G Madhavi Latha and Amit Somwanshi (2009), "Effect of reinforcement on the bearing capacity of square footings on sand. Geotextiles and Geo-membranes 27 (2009) 409-422, 8 May 2009.

[5]. K. M. Lee \& V.R. Manjunath (2000), Soil-geotextile interface friction by direct shear tests.

[6]. Temel Yetimoglu, OMER SALBAS (2003), "A study on shear strength of sands reinforced with randomly distributed discrete Fibres" Atac 2 Sk., Umut Apt. 52/16, Kızllay-Ankara 06410, Turkey, Geotextiles and Geomembranes, 21 103-110. [7]. Fauziah Ahmad, Farshid Bateni, Mastura Azmi (2009), "Performance evaluation of silty sand reinforced with fibres" Geotextiles and Geo-membranes 28 (2010) 93-99.

[8]. G.L Sivakumar Babu \& A.K Vasudevan (2008), "Strength and stiffness response of coir fibre reinforced Tropical soil".

\section{BIOGRAPHIE}

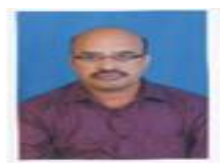

R. Sridhar, Assoc. Professor, Alva,s Institute of Engg.\& Technology, Moodbidri 